\title{
Benzimidazole derivative, BMT-1, induces apoptosis in multiple myeloma cells via a mitochondrial-mediated pathway involving $\mathrm{H}^{+} / \mathrm{K}^{+}$-ATPase inhibition
}

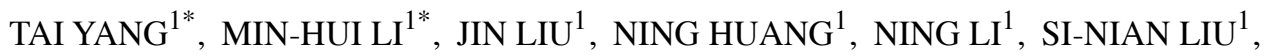 \\ YANG LIU ${ }^{1}$, TAO ZHANG ${ }^{2}$, QIANG ZOU ${ }^{1}$ and $\mathrm{HUA} \mathrm{LI}^{2}$ \\ ${ }^{1}$ Department of Immunology, Chengdu Medical College, Chengdu, Sichuan 610083; \\ ${ }^{2}$ Department of Oncology, Chengdu Military General Hospital, Chengdu, Sichuan 610083, P.R. China
}

Received February 5, 2014; Accepted March 4, 2014

DOI: $10.3892 /$ or.2014.3122

\begin{abstract}
H-benzimidazol-2-yl)-4,5,6,7-tetrahydro-2Hindazol-3-ol (BMT-1), a bicyclic compound, belongs to the benzimidazole group and consists of the fusion of benzene and imidazole. The objective of the present study was to assess the effect of BMT-1 on the proliferation of multiple myeloma (MM) cells and identify whether BMT-1 induces apoptosis in MM cells. Our results showed a dose- and time-dependent decrease in the proliferation of MM cells treated with BMT-1. Further studies revealed that the antiproliferative effects of BMT-1 were caused by induction of apoptosis with activation of caspase-3 and cleavage of poly(ADP-ribose) polymerase in MM cells. In addition, BMT-1 induced the loss of mitochondrial membrane potential resulting in the activation of caspase- 8 and -9 . Furthermore, the MM cells treated with BMT-1 showed a more acidic intracellular $\mathrm{pH}(\mathrm{pHi})$ as indicated by a lower FL1/FL2 ratio caused by inhibition of $\mathrm{H}^{+} /$ $\mathrm{K}^{+}$-ATPase. Collectively, these findings demonstrated that a decrease in $\mathrm{pHi}$, caused by $\mathrm{H}^{+} / \mathrm{K}^{+}$-ATPase inhibition induced by BMT-1, triggered the dysfunction of the mitochondria resulting in the apoptosis of MM cells. Therefore, BMT-1 may be used as a lead compound for the design and development of new agents with which to treat MM and other forms of cancer.
\end{abstract}

\section{Introduction}

Multiple myeloma (MM) is a malignant monoclonal plasma cell disorder that is characterized by end-organ damage

Correspondence to: Dr Tao Zhang or Dr Hua Li, Department of Oncology, Chengdu Military General Hospital, 270 Tianhui Road, Rongdu Avenue, Jinniu, Chengdu, Sichuan 610083, P.R. China

E-mail: zhangtao269@126.com

E-mail: huali99@gmail.com

${ }^{*}$ Contributed equally

Key words: benzimidazole derivative, multiple myeloma, apoptosis, $\mathrm{H}^{+} / \mathrm{K}^{+}$-ATPase such as anemia, hypocalcemia, renal insufficiency or bone lesions $(1,2)$. The conventional treatment of MM includes radiation and chemotherapy. Various chemotherapy drugs, including doxorubicin, thalidomide, lenalidomide and bortezomib have improved patient outcomes. However, MM remains incurable, and the median survival time for MM patients is 3-5 years. Therefore, it is important to continue the search for novel, safe and effective reagents to treat MM and improve the treatment efficacy of this fatal disease. The main thrust of the present study was towards the identification of small bioactive molecules that have the greatest potential in combating cancer and to understand the mechanism of action of these bioactive molecules at the molecular and cellular levels.

Benzimidazole is a heterocyclic aromatic organic compound that consists of the fusion of benzene and imidazole. This particular structure can form hydrogen bonds in vivo with enzymes and receptors that exhibit varied bioactivities. Benzimidazole derivatives are currently found in many commercial drugs that are used in the clinical treatment of numerous diseases (3-6). The anticancer properties of benzimidazole-based compounds are also extremely valuable. It has been reported that benzimidazole derivatives induce anticancer effects in many human cancer cells (7-10). We identified 2-(1H-benzimidazol-2-yl)-4,5,6,7-tetrahydro-2Hindazol-3-ol (BMT-1), a benzimidazole derivative, as a potent anti-myeloma drug from a drug screening library (Fig. 1A). Thus, the focus of the present study was to explore the potential of the benzimidazole compound BMT-1 with respect to apoptosis in MM cells.

Apoptosis is a physiological mechanism for eliminating malignant cells or cancer cells without eliciting significant damage to normal cells (11). Thus, agents that suppress the proliferation of malignant cells by inducing apoptosis may represent a useful mechanistic approach to both chemoprevention and chemotherapy of cancer. In the present study, we examined the cytotoxic effect of BMT-1 on human MM cells. Herein, we demonstrated that BMT-1 induced the apoptosis of MM1.S and MM1.R human MM cells via a mitochondrialmediated mechanism with loss of mitochondrial membrane potential resulting in the activation of caspase- 8 and -9 . 
To understand the mechanisms of apoptosis induced by the small molecule BMT-1, the inhibitory effect of BMT-1 on $\mathrm{H}^{+} / \mathrm{K}^{+}$-ATPase was evaluated since BMT-1 is a benzimidazole derivative. It has already been observed that most well-known pharmaceuticals containing the benzimidazole core are $\mathrm{H}^{+} / \mathrm{K}^{+}$-ATPase pump or proton pump inhibitors (PPIs) (12). The $\mathrm{H}^{+} / \mathrm{K}^{+}$-ATPase is often highly expressed in cancer cells to maintain the reversed $\mathrm{pH}$ gradient, including a constitutively higher intracellular $\mathrm{pH}(\mathrm{pHi})$ and a lower extracellular $\mathrm{pH}$ (pHe) to facilitate the indicated adaptive behaviors $(13,14)$. As dysregulated $\mathrm{pH}$ is also an adaptive feature of most types of cancers, drugs that inhibit proton pumps in cancer cells may lower the intracellular $\mathrm{pH}$ of cancer cells and slow proliferation and promote apoptosis in various cancer cell lines (15). Many human tumors, including melanoma, osteosarcoma, lymphomas and various adenocarcinomas, are responsive to PPIs (16). Therefore, the objective of the present study was to investigate BMT-1-induced apoptosis and explore whether the inhibition of $\mathrm{H}^{+} / \mathrm{K}^{+}$-ATPase is a potential mechanism by which BMT-1 inhibits MM cell survival.

\section{Materials and methods}

Chemicals. BMT-1 was obtained from Chembridge, Inc. (San Diego, CA, USA). Dimethyl sulfoxide (DMSO; Sigma-Aldrich Co., St. Louis, MO, USA) was used to dissolve BMT-1.

Antibodies and reagents. Caspase-3, cleaved capase-3, caspase-8, cleaved capase-8, poly(ADP-ribose) polymerase (PARP) and glyceraldehyde 3-phosphate dehydrogenase (GAPDH) were obtained from Cell Signaling Technology (Beverly, MA, USA). The $\mathrm{H}^{+} / \mathrm{K}^{+}$-ATPase $\beta$-subunit (ATP4B) antibody was purchased from Abnova (Abnova, Taipei, Taiwan). The mitochondrial staining kit was purchased from Sigma (Sigma-Aldrich Co.). The $\mathrm{H}^{+} / \mathrm{K}^{+}$-ATPase kit was from Nanjing Jiancheng Biochemical Institute (Nanjing, China).

Cells culture and treatment. The MM cell lines, MM1.S, MM1.R, RPMI8226 and U-266, were obtained from the American Type Culture Collection (ATCC) (Rockville, MD, USA). The cell lines were maintained in RPMI-1640 medium supplemented with $10 \%$ (v/v) fetal bovine serum (FBS) (both from Gibco, Gaithersburg, MD, USA), L-glutamine and antibiotics (Gibco Laboratories, Grand Island, NY, USA). The MM cell liness were treated with varying concentrations of BMT-1 for the indicated times as described in the figure legends.

Measurement of cell growth inhibition and data analysis. Cell growth inhibition was performed in accordance with the protocol from the Drug Evaluation Branch, National Cancer Institute $(17,18)$. Briefly, cells were plated at an appropriate density in 96-well plates in RPMI-1640 with 10\% (v/v) FBS and allowed to attach overnight. The cells were exposed to different drug dilutions for $48 \mathrm{~h}$. Using the absorbance measurements [time zero $(\mathrm{Tz})$, control growth $(\mathrm{C})$ and test growth in the presence of drug at the four concentrations (Ti)]; the percentage of growth was calculated at each of the drug concentration levels. The percentage of growth inhibition was calculated as: $[(\mathrm{Ti}-\mathrm{Tz}) /(\mathrm{C}-\mathrm{Tz})]$ x 100 for concentrations for which $\mathrm{Ti} \geq \mathrm{Tz}$ and $[(\mathrm{Ti}-\mathrm{Tz}) / \mathrm{Tz}]$ x 100 for concentrations for which Ti $\leq \mathrm{Tz}$. Growth inhibition of $50 \%\left(\mathrm{GI}_{50}\right)$ was calculated from $[(\mathrm{Ti}-\mathrm{Tz}) /(\mathrm{C}-\mathrm{Tz})] \mathrm{x} 100=50$, which is the drug concentration resulting in a $50 \%$ reduction in net protein increase.

Viability of lymphocytes and BMT-1 exposure. To detect the effect of BMT-1 in primary cells, peripheral blood mononuclear cells (PBMCs) were isolated from whole human blood following informed consent. The cells were treated with different concentrations of BMT-1 for $72 \mathrm{~h}$. PBMCs were counted and analyzed using CellQuest software BD Accuri C6 Flow Cytometer and analyzed using CFlow software (version 1.0.243.1) (both from BD Accuri, Ann Arbor, MI, USA). The study protocol was approved by the Institutional Review Board (IRB) of Chengdu Medical College.

Analysis of changes in mitochondrial membrane potential. Cells $\left(5 \times 10^{5}\right)$ treated with varying concentrations of BMT-1 were stained with $\mathrm{JC}-1$ from the mitochondrial staining kit (Sigma) at $37^{\circ} \mathrm{C}$ for $20 \mathrm{~min}$ following the manufacturer's procedures. Changes in cellular mitochondrial membrane potential were quantified by measuring the fluorescence intensity emission ratios at $590 \mathrm{~nm}$ (red)/525 $\mathrm{nm}$ (green) using the BD Accuri C6 Flow Cytometer and CFlow software (version 1.0.227.4; BD Accuri). The widely used mitochondrial membrane potential disruptor valinomycin was used as a positive control.

Cell cycle analysis and detection of apoptosis. MM cells $\left(5 \times 10^{5}\right)$ were cultured for $24 \mathrm{~h}$ in media alone or with varying concentrations of BMT-1. The cells were harvested, washed with ice-cold phosphate-buffered saline (PBS), fixed with $70 \%(\mathrm{v} / \mathrm{v})$ ethanol for $2 \mathrm{~h}$, and pretreated with $100 \mu \mathrm{g} / \mathrm{ml}$ RNAse (Sigma) for $1 \mathrm{~h}$. Cells were stained with propidium iodide (PI) $(20 \mu \mathrm{g} / \mathrm{ml}$; Sigma), and the cell cycle profile was determined using the BD Accuri C6 Flow Cytometer and CFlow software (version 1.0.227.4). Dual staining with Fluos-labeled Annexin V and PI was carried out to detect the induction of apoptotic cell death. Following treatment of $2 \times 10^{5}$ cells with a test agent for $24 \mathrm{~h}$, cells were washed with PBS and re-suspended in $100 \mu \mathrm{l}$ binding buffer containing Annexin V-Fluos and PI (Annexin V-Fluos staining kit; Roche). After 15 min of incubation at room temperature, cells were analyzed on a BD Accuri C6 Flow Cytometer for the presence of Annexin V-Fluos-positive/PI-negative apoptotic cell populations.

Western blot analysis. MM cells were treated with varying concentrations of BMT-1 for the indicated times, as described in the figure legends. Cells were lysed for $30 \mathrm{~min}$ in ice-cold lysis buffer (BioTeke Corporation, Beijing, China). The cell lysates were cleared by centrifugation for $15 \mathrm{~min}$ at $12,000 \mathrm{x} \mathrm{g}$ and used for immunoprecipitation. Proteins (50 $\mu \mathrm{g} /$ lane $)$ were resolved by sodium dodecyl sulfate-polyacrylamide gel electrophoresis (SDS-PAGE) and then transferred to a PVDF membrane. The membranes were blocked with a $5 \%(\mathrm{w} / \mathrm{v})$ milk solution for $1 \mathrm{~h}$ and incubated in the following primary antibodies: caspase-3, cleaved capase-3, caspase-8, cleaved capase-8, PARP and GAPDH. 
A<smiles>Oc1c2c(nn1-c1nc3ccccc3[nH]1)CCCC2</smiles>

C

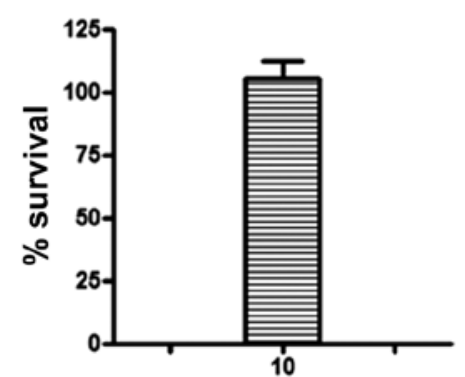

BMT-1 ( $\mu \mathrm{M})$
B
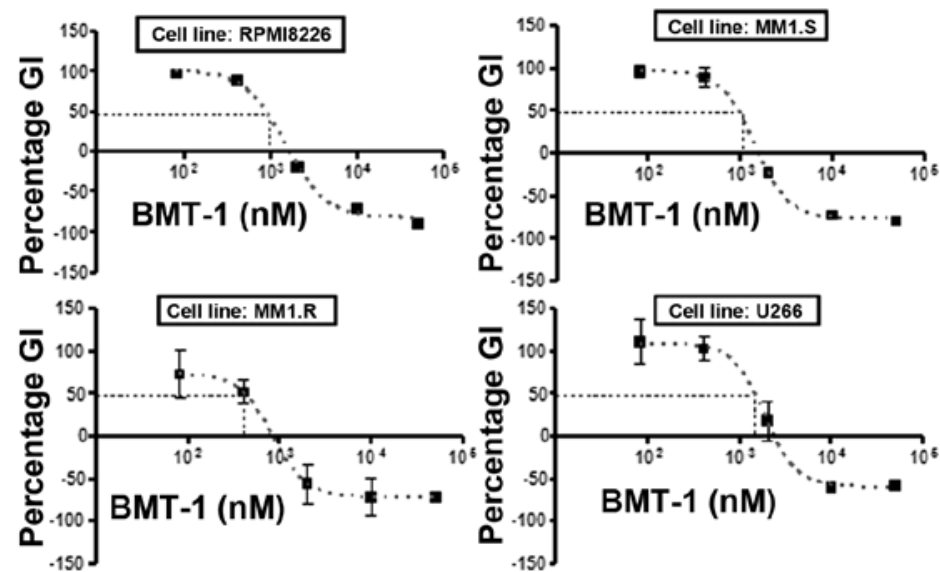

Figure 1. (A) Molecular structure of 1H-benzimidazol-2-yl)-4,5,6,7-tetrahydro-2H-indazol-3-ol (BMT-1). (B) BMT-1 treatment decreased the viability of the MM cell lines in a dose-dependent manner with an $\mathrm{IC}_{50}$ ranging from 889 to $1476 \mathrm{nM}$. (C) Survival of PBMCs after a 24-h incubation with BMT-1 (10 $\mu \mathrm{M}$ ). Cells were counted using a BD Accuri C6 Flow Cytometer. Survival of untreated control cells represented 100\% viability. BMT-1 was not toxic to lymphocytes. MM, multiple myeloma.

Evaluation of cytosolic $p H$. The effects of BMT-1 on cytosolic $\mathrm{pH}$ were evaluated by flow cytometry using the $\mathrm{pH}$-sensitive fluorescent probe BCECF-AM (Beyotime Institute of Biotechnology, China). Approximately $1 \times 10^{6}$ cells were incubated at $37^{\circ} \mathrm{C}$ for $30 \mathrm{~min}$ in $1 \mathrm{ml} \mathrm{RPMI}$ containing $1 \mu \mathrm{mol} / 1 \mathrm{BCECF}-\mathrm{AM}$. The cells were then washed in Hank's balanced salt solution (HBSS), placed on ice, and analyzed with a FACSCalibur equipped with a 488-nm argon laser collecting the emission of BCECF-AM in the FL1 and FL2 channels $(19,20)$. The relative cytosolic $\mathrm{pH}$ of individual cells was displayed in a two-dimensional dot-plot showing their fluorescence intensity at 533/30 nm (FL1, base) and 585/40 nm (FL2, acid).

Measurements of ATPase activity in MM cells. Cells $\left(5 \times 10^{7}\right)$ were collected by centrifugation at $600 \mathrm{x}$ g for $5 \mathrm{~min}$ at $4^{\circ} \mathrm{C}$, and washed with ice-cold $0.9 \%(\mathrm{w} / \mathrm{v})$ saline solution. Cells were then homogenized on ice with a dounce tissue grinder, and the supernatant was transferred into tubes with final BMT-1 concentrations of $0,25,50$ and $100 \mu \mathrm{M}$. To analyze the activity of $\mathrm{H}^{+} / \mathrm{K}^{+}$-ATPase, the OD value at $660 \mathrm{~nm}$ was detected according to the procedure of the $\mathrm{H}^{+} / \mathrm{K}^{+}$-ATPase kit (Nanjing Jiancheng Biochemical Institute, Nanjing, China) using the formula: Activity of $\mathrm{H}^{+} / \mathrm{K}^{+}$-ATPase $(\mathrm{U} / \mathrm{mg}$-prot $)=\left(\mathrm{OD}_{\text {test }}-\mathrm{OD}_{\text {control }}\right) / \mathrm{OD}_{\text {standard }} \mathrm{x}$ standard concentration $(0.5 \mu \mathrm{mol} / \mathrm{ml}) \times(60 \mathrm{~min} / 10 \mathrm{~min}) \times$ dilution ratio $(4.8) /$ protein concentration $(\mathrm{mg} / \mathrm{ml})$.

\section{Results}

Effect of BMT-1 on MM and normal cells. We first examined the growth inhibitory effect of BMT-1 on MM cell lines. By using the CCK- 8 assay, we found that BMT-1 markedly inhibited the growth of U266, RPMI-8226, MM.1S and MM.1R cells with $\mathrm{IC}_{50}$ values of 889 to $1476 \mathrm{nM}$ (Fig. 1B). To examine the inhibition of BMT-1 on cancer cell growth that was not caused by toxicity, we performed in vitro analyses using cultured PBMCs in the absence and presence of BMT-1. As shown in Fig. 1C, non-significant lymphotoxicity was observed after exposure to BMT-1 at a concentration of $10 \mu \mathrm{M}$. Overall, these results suggest that BMT-1 inhibits the growth of MM cells that is not related to toxicity.

BMT-1 causes accumulation of MM cells in the sub-G1 phase. To further confirm that BMT-1 inhibits proliferation of MM cells through induction of cell cycle arrest, we analyzed the cell cycle distribution after PI staining. The percentage of MM1.S and MM1.R cells in the sub-G1 (apoptotic cells) phase was significantly elevated as the concentration of BMT-1 increased. For example, $10.3 \pm 3.6$ and $14.8 \pm 4.6 \%$ of MM1.S cells existed in the sub-G1 region following treatment with 2 and $4 \mu \mathrm{M}$ BMT-1 for $24 \mathrm{~h}$, respectively (Fig. 2A and B). Collectively, we observed a significant increase in the sub-G1 cell population indicating the occurrence of apoptosis that was associated with a reduction in the G0-G1 fraction.

BMT-1 causes apoptosis in MM cells. To confirm whether the growth inhibition of BMT-1 was caused by apoptosis, the percentage of Annexin V-positive cells was measured using flow cytometry. A dose-dependent increase in the population of apoptotic cells was observed (Fig. 3A). BMT-1 at a concentration of $4 \mu \mathrm{M}$ induced 17.5 and $19.3 \%$ apoptosis in the MM1.S and MM1.R cells, respectively (cells positive for Annexin V, negative for PI) after $24 \mathrm{~h}$ when compared with 4.6\% (MM1.S) and 5.1\% (MM1.R) in the negative control (DMSO). To evaluate the contribution of active caspases in BMT-1-induced apoptosis, we evaluated cells carrying activated caspase- 3 and PARP and found that pro-caspase- 3 


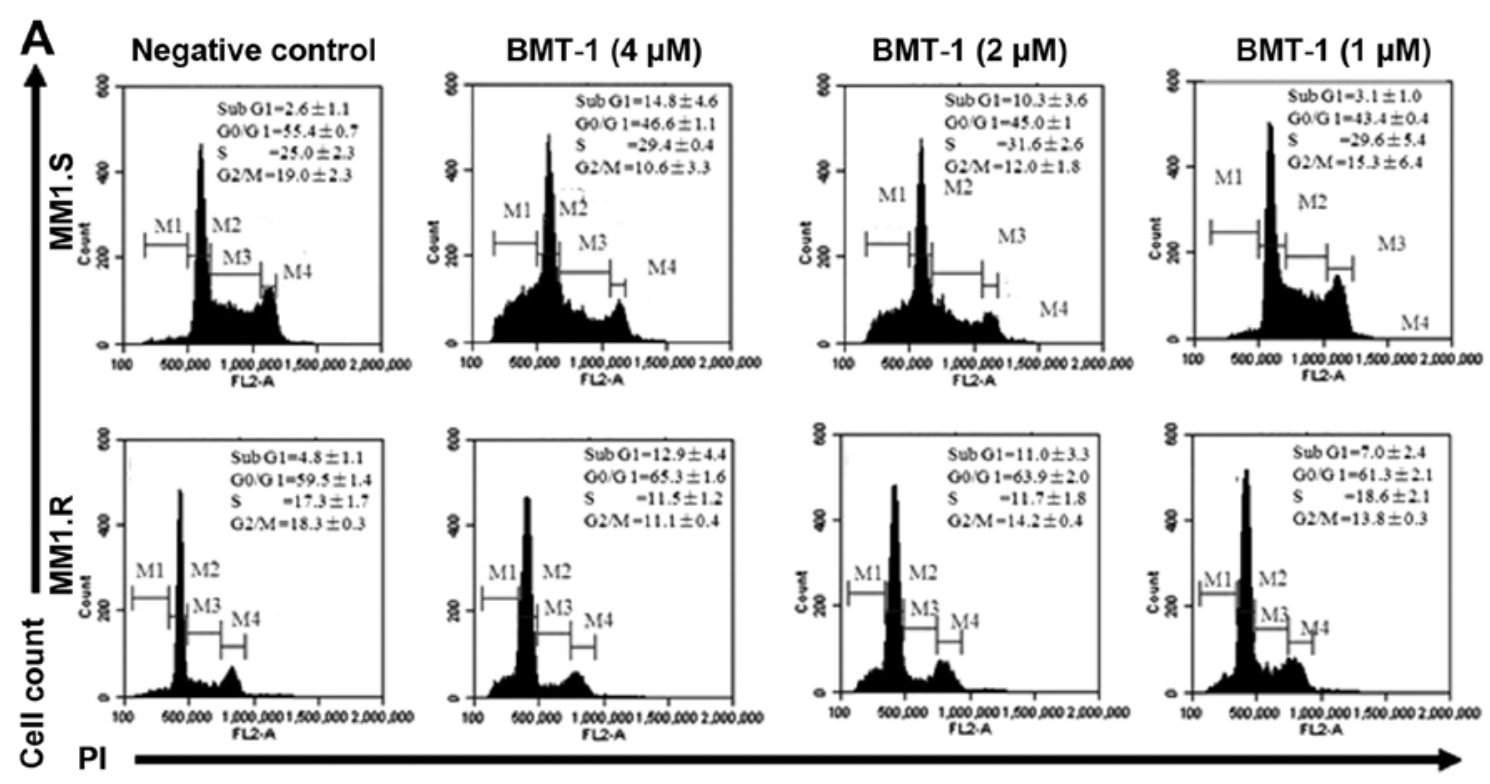

B
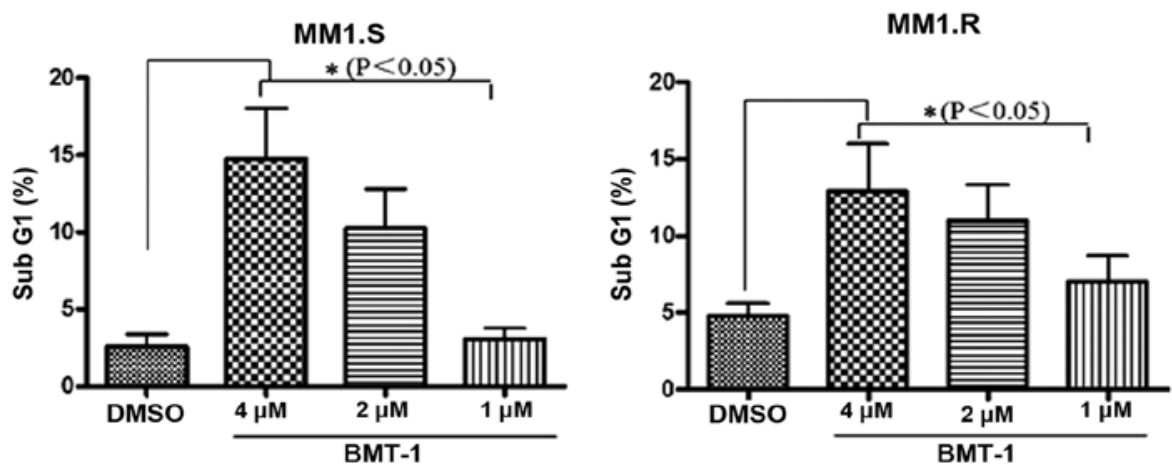

Figure 2. BMT-1 causes accumulation of MM cells in the sub-G1 phase. (A) MM1.S and MM1.R cells $\left(5 \times 10^{5}\right)$ were treated with varying concentrations of BMT-1 for $24 \mathrm{~h}$, after which the cells were washed, fixed, stained with PI and analyzed for DNA content by flow cytometry. (B) The sub-G1 population was evaluated by histogram analyses. Concentration-response columns were analyzed with GraphPad Prism software. Comparisons between groups and within groups were carried out by one-way analysis of variance (ANOVA) and " $\mathrm{P}<0.05$ was considered significant when compared with the control.

and pro-PARP were cleaved to yield smaller fragments in MM cells following BMT-1 treatment (Fig. 3B). These data indicated that BMT-1 indeed induced apoptosis in cancer cells, which was consistent with the results of the growth-inhibition assay.

Effect of BMT-1 on mitochondrial membrane potential. The effect of BMT-1 on mitochondrial membrane potential was monitored. Any event that dissipates mitochondrial membrane potential prevents the accumulation of JC-1 in the mitochondria and thus, the dye is dispersed throughout the entire cell leading to a shift from red (J-aggregates) to green fluorescence (JC-1 monomers). As shown in Fig. 4A, after an 8-h drug exposure, BMT-1 depolarized the mitochondrial membranes in a concentration-dependent manner, a time-point when no cellular morphological change could be observed. Most control cells fluoresced red, while BMT-1-treated cells turned green. During mitochondrial-dependent apoptosis, the instability of mitochondria initiates the formation of the apoptosome and the sequential activation of caspase- 8 and $-9(21,22)$. The present study found that BMT-1 induced the loss of mitochon- drial membrane potential resulting in activation of caspase- 8 and -9 (Fig. 4B). These results suggest that the mitochondrial dependent pathway is involved in BMT-1-trigged MM cell apoptosis.

As the energy power plants of the cell, mitochondria generate ATP by utilizing the proton electrochemical gradient potential (23). Thus, $\mathrm{H}^{+} / \mathrm{K}^{+}$-ATPase is extremely important to mitochondria since it uses energy to transport protons from the matrix of the mitochondrion to the inner and outer mitochondrial membranes. Therefore, $\mathrm{H}^{+} / \mathrm{K}^{+}$-ATPase inhibition disrupts the proton electrochemical gradient to induce a loss of mitochondrial function. In the present study, BMT-1 strongly depolarized mitochondrial membranes. Furthermore, all of the currently marketed $\mathrm{H}^{+} / \mathrm{K}^{+}$-ATPase inhibitors (e.g., omeprazole, lansoprazole and pantoprazole) are benzimidazole derivatives (24-26). Therefore, we proposed that BMT-1 would also inhibit $\mathrm{H}^{+} / \mathrm{K}^{+}$-ATPase activity.

$H^{+} / K^{+}$-ATPase inhibition is associated with acidification of cytosolic pH in BMT-1-treated cells. The expression of $\mathrm{H}^{+} / \mathrm{K}^{+}$-ATPase in MM cells was determined by western blot 
A
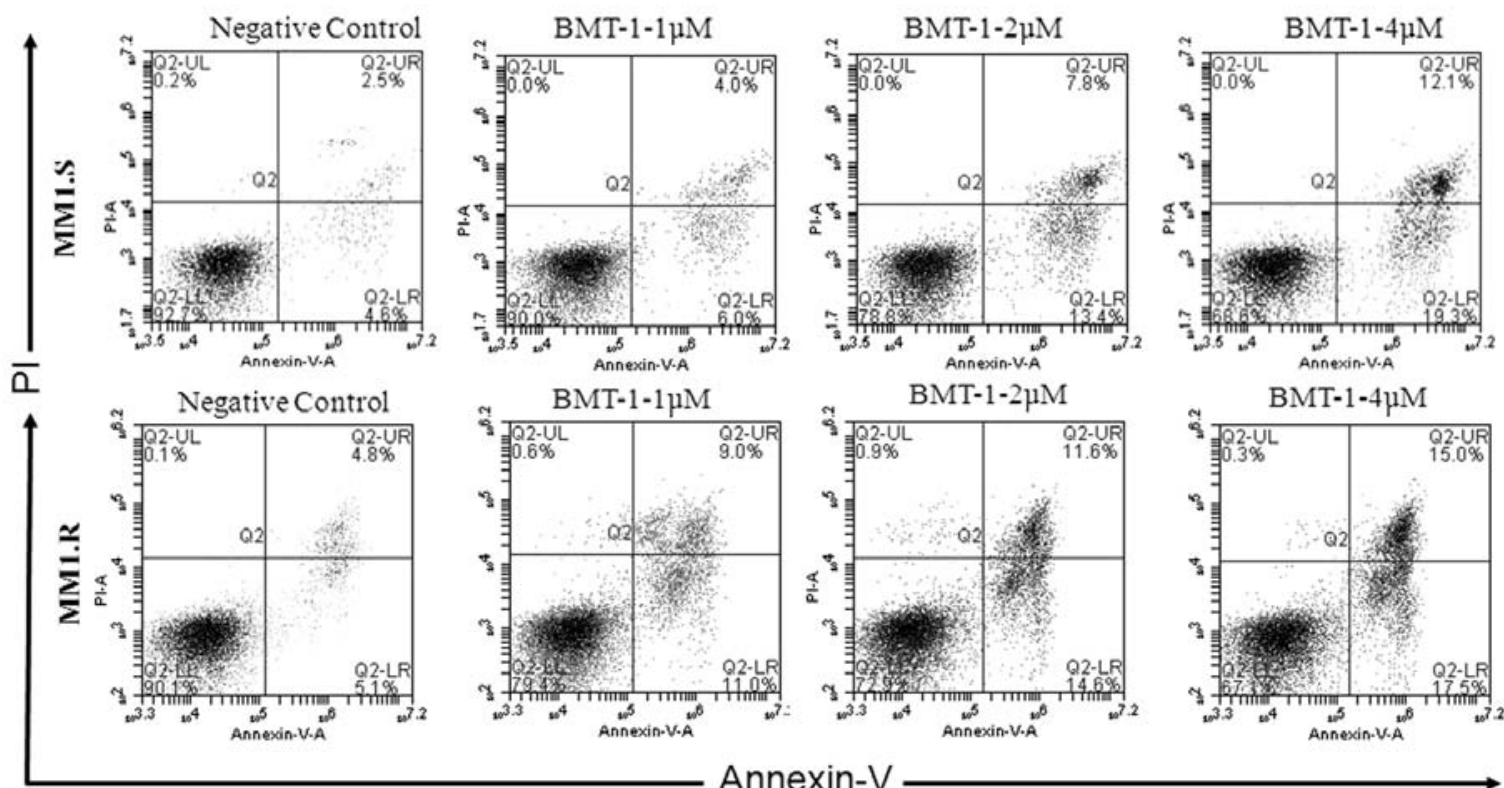

B
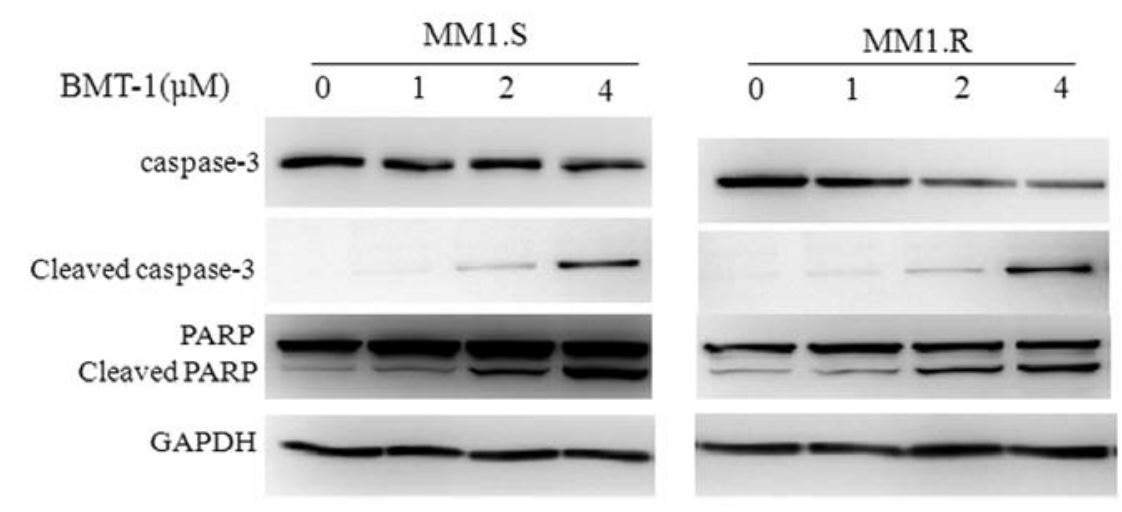

Figure 3. BMT-1 induces MM cell apoptosis. (A) Effects of BMT-1 on cell viability and apoptosis in the MM1.S and MM1.R cells were determined by dual staining with Annexin V and PI. (B) MM.1S and MM.1R MM cells were treated with BMT-1 for $8 \mathrm{~h}$, harvested, and the total protein lysate was subjected to western blot analysis using antibodies against caspase-3, cleaved caspase-3, PARP or GAPDH. PI, propidium iodide; MM, multiple myeloma; PARP, poly(ADP-ribose) polymerase; GAPDH, glyceraldehyde 3-phosphate dehydrogenase.

analysis (Fig. 5A). To further confirm whether inhibition of $\mathrm{H}^{+} / \mathrm{K}^{+}$-ATPase activity is induced by BMT-1, the homogenized MM cells were treated with different concentrations of BMT- 1 for $30 \mathrm{~min}$ and the activity of $\mathrm{H}^{+} / \mathrm{K}^{+}$-ATPase was detected. Compared with the control group $(0 \mu \mathrm{M})$, BMT-1 at every concentration and lansoprazole (LAN), a positive inhibitor of $\mathrm{H}^{+} / \mathrm{K}^{+}$-ATPase, both inhibited $\mathrm{H}^{+} / \mathrm{K}^{+}$-ATPase from the MM1.S and MM1.R cells (Fig. 5B), while the activity of $\mathrm{H}^{+} / \mathrm{K}^{+}$-ATPases was not inhibited by the negative control inhibitor bortezomib (BOR). $\mathrm{H}^{+} / \mathrm{K}^{+}$-ATPases are ion pumps that use the energy of ATP hydrolysis to transport protons $\left(\mathrm{H}^{+}\right)$ in exchange for potassium ions against their concentration gradients. Thus, the inhibition of $\mathrm{H}^{+} / \mathrm{K}^{+}$-ATPases by BMT-1 could block $\mathrm{H}^{+}$extrusion, resulting in proton accumulation and intracellular acidification, which would terminate or limit the growth of cancer cells $(19,27)$. To explore this possibility, the effect of BMT-1 on intracellular $\mathrm{pH}$ changes was examined; we used BCECF-AM as a pH-dependent fluorescent dye. Flow cytometry was used to measure intracellular fluorescence of BCECF-labeled MM cells, which were exposed to BMT-1. Treated cells exhibited a strong decrease in the FL1/FL2 ratio (indicating an acidic cytosolic $\mathrm{pH}$ ), whereas little change in the emission ratio of control cells was observed. Hence, the results indicated that the intracellular $\mathrm{pH}$ was reduced in the cells exposed to BMT-1 (Fig. 5C).

\section{Discussion}

In drug discovery, low toxicity and high efficacy are the main criteria in selecting a 'hit' compound (28). BMT-1 is one such compound, and its potential suitability for use in the treatment of cancer was investigated in the present study. Cultures of PBMCs were used to determine the effect of BMT-1 on normal primary cells. The data showed that BMT-1 displayed higher efficacy against MM cancer cells than normal PBMCs with 10-fold selectivity. BMT-1 exhibited no cytotoxicity in the 
A
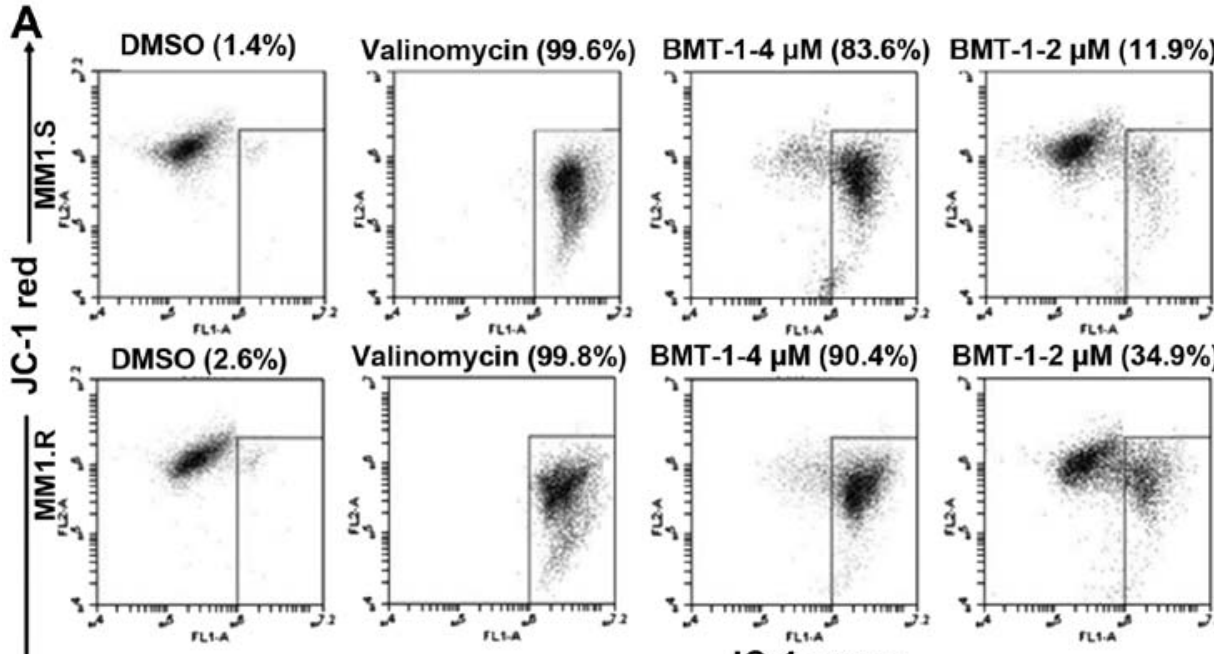

BMT-1-1 $\mu \mathrm{M}(6.6 \%)$
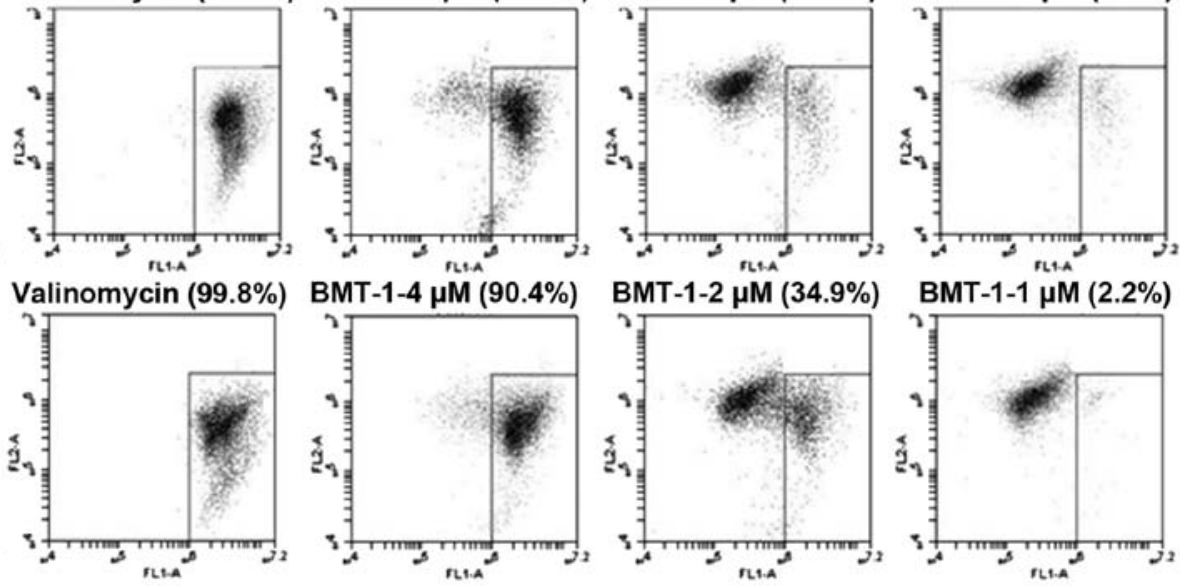

BMT-1-1 $\mu \mathrm{M}(2.2 \%)$

$\mathrm{JC}-1$ green

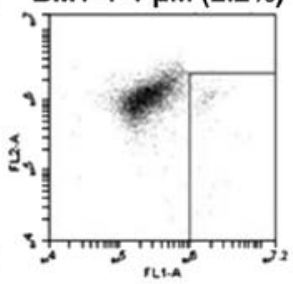

B

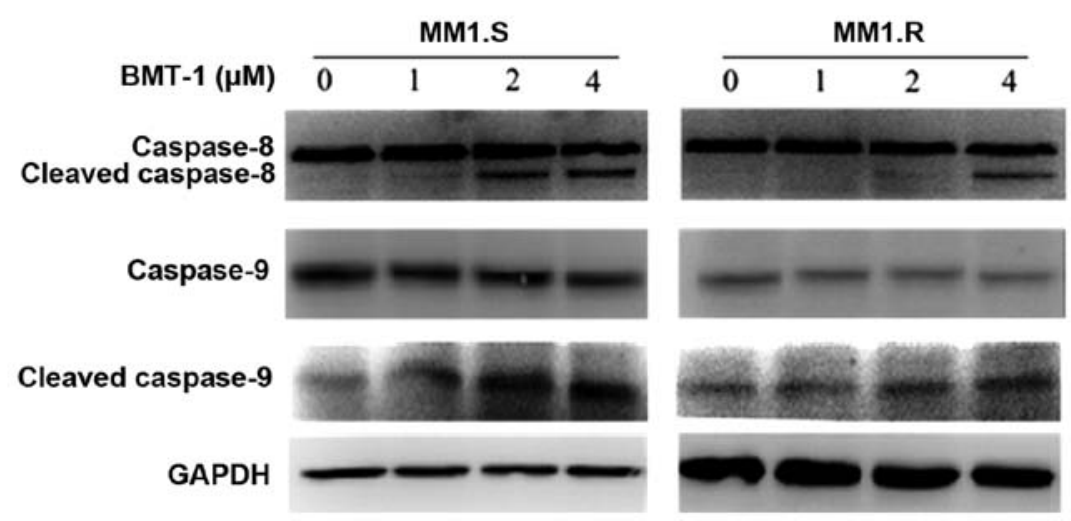

Figure 4. (A) Human MM cell lines MM1.S and MM1.R were treated with BMT-1 and then stained with JC-1 before flow cytometry analysis. Mitochondrial membrane potential loss was observed as a decrease in JC-1 red fluorescence $(585 \pm 40 \mathrm{~nm}$; FL-2) and an increase in JC- 1 green fluorescence $(530 \pm 30 \mathrm{~nm}$; FL-1). (B) MM.1S and MM.1R MM cells were treated with BMT-1 $(1,2$ and $4 \mu \mathrm{M})$ for $8 \mathrm{~h}$, harvested, and the total protein lysate was subjected to western blot analysis using antibodies against caspase-8, cleaved caspase-8, caspase- 9 and cleaved caspase-9. MM, multiple myeloma.

primary cells at a concentration of $10 \mu \mathrm{M}$ even following a 96-h treatment. Therefore, BMT-1 selectively induced cell death in cancer cells with low cytotoxicity to normal cells, which suggests it could be used as a potential chemotherapeutic agent against cancer.

Benzimidazole derivatives provide useful precursors or subunits for the development of molecules of pharmaceutical or biological interest. It has previously been reported that benzimidazole derivatives induce anti-mitotic and antitumor effects in many human cancer cell lines (29-32). However, the antitumor effects of benzimidazole derivatives on MM cells are mostly unknown. Our experimental results showed that BMT-1 exhibits obvious cytotoxicity against MM1.S and MM1.R cells, based on the significant $\mathrm{IC}_{50}$ value of $1 \mu \mathrm{M}$ (Fig. 1). The present study clearly and convincingly showed that BMT-1 induced MM cell apoptosis in a dosedependent and time-dependent manner.

Mitochondrial depolarization is a well-characterized event in apoptosis. In this process, the electrochemical gradient across the mitochondrial membrane breaks down. To elucidate the mechanism of apoptosis, we investigated the effects of BMT-1 on mitochondrial membrane potential. Our results showed that BMT-1 strongly depolarized mitochondrial membranes in a concentration-dependent manner in these cell lines (Fig. 2), which is in agreement with our Annexin V and cell cycle results.

$\mathrm{H}^{+} / \mathrm{K}^{+}$-ATPases or proton pumps play a key role in the function of the mitochondria, as they use the energy made available from electron transfer reactions to transport protons across the inner mitochondrial membrane and create an electrochemical gradient used for the production of ATP (33). Thus, $\mathrm{H}^{+} / \mathrm{K}^{+}$-ATPase inhibition could disrupt the proton electrochemical gradient and lead to the destruction of mitochondria. In the present study, BMT-1 was observed to strongly depolarize the mitochondrial membrane potential. We wanted to investigate whether BMT-1 possesses the characteristic of many other benzimidazole derivatives in being able to inhibit $\mathrm{H}^{+} / \mathrm{K}^{+}$-ATPase activity. Our results showed that BMT-1 and the positive $\mathrm{H}^{+} / \mathrm{K}^{+}$-ATPase inhibitor, LAN, significantly inhibited $\mathrm{H}^{+} / \mathrm{K}^{+}$-ATPases from the MM1.S and MM1.R cells in a dose-dependent manner (Fig. 5B), while the activity of $\mathrm{H}^{+} / \mathrm{K}^{+}$-ATPases was not inhibited by a negative control inhibitor BOR. Furthermore, it was believed that impaired inhibition of $\mathrm{H}^{+} / \mathrm{K}^{+}$-ATPases by BMT-1 would lead to intracellular acidification, limiting cancer cell growth. To explore this possibility, the effect of BMT-1 on intracellular $\mathrm{pH}$ changes 
A

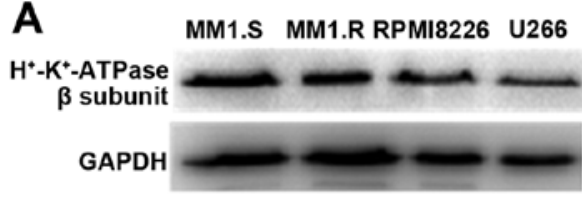

B

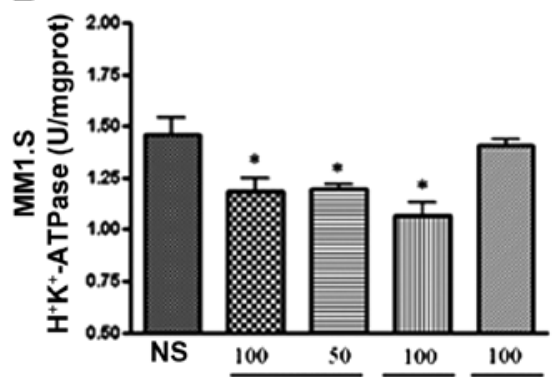

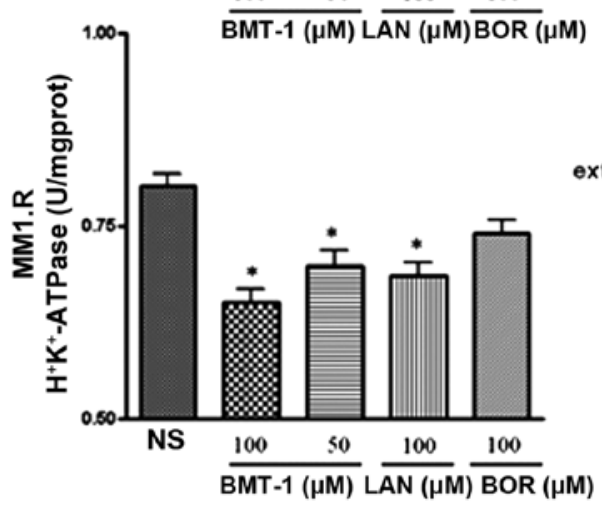

C

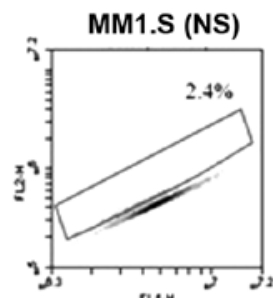

M1.R (NS)

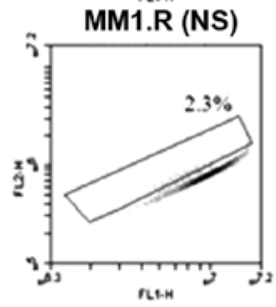

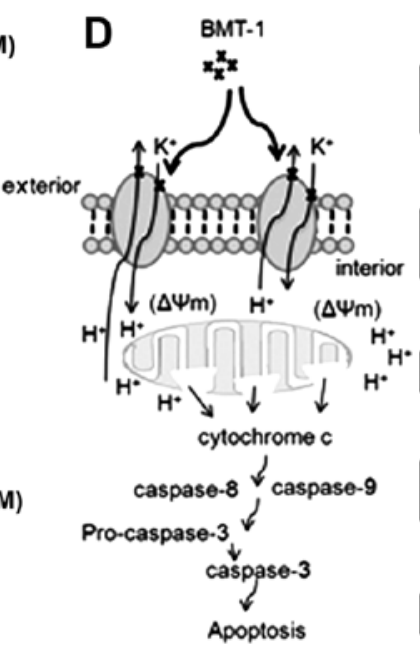
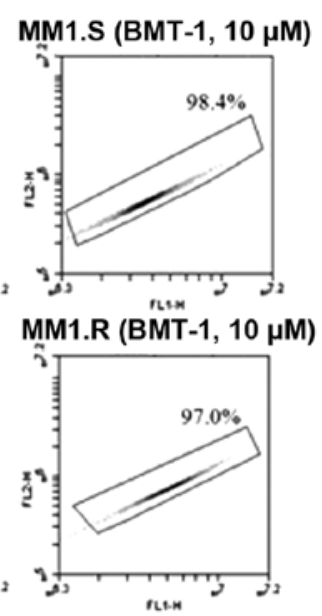

Blockage of intracellular proton extrusion

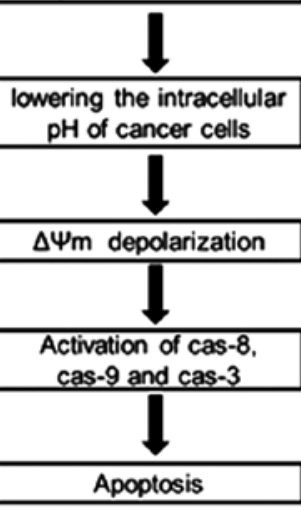

Figure 5. (A) Expression of $\mathrm{H}^{+} / \mathrm{K}^{+}$-ATPase in MM cell lines was identified by western blot analysis. (B) BMT-1 inhibits the activity of $\mathrm{H}^{+} / \mathrm{K}^{+}$-ATPase in the MM1.S and MM1.R cells $(n=4)$. Concentration-response columns were analyzed with GraphPad Prism software. Comparisons between groups and within groups were carried out by one-way analysis of variance (ANOVA) and ${ }^{*} \mathrm{P}<0.05$ was considered significant when compared with the control. (C) Change in cytosolic $\mathrm{pH}$ induced by BMT-1 $(10 \mu \mathrm{M})$ was evaluated in MM1.S and MM1.R cells treated for $6 \mathrm{~h}$ and loaded with the pH-sensitive fluorescent probe BCECF-AM. The population in the region R1 contains cells with a more acidic intracellular pH as indicated by a lower FL1/FL2 ratio. (D) Proposed model of the mechanism of BMT-1-induced apoptosis. BMT-1 causes mitochondrial-dependent apoptosis indicated by sequential events including $\mathrm{H}^{+} / \mathrm{K}^{+}-\mathrm{ATPase}$ inhibition, intracellular acidification, mitochondrial depolarization and activation of caspase-9, -8 and -3 . MM, multiple myeloma.

was examined; we used BCECF as a pH-dependent fluorescent dye. The results indicated that the intracellular $\mathrm{pH}$ was reduced in the cells exposed to BMT-1 (Fig. 5C).

Cancer cells have an inverse $\mathrm{pH}$ gradient when compared with normal differentiated adult cells, including a constitutively higher intracellular $\mathrm{pH}(\mathrm{pHi})$ and a lower extracellular $\mathrm{pH}(\mathrm{pHe})$, which facilitate the indicated adaptive behaviors $(13,14)$. To avoid intracellular acidification under such conditions, tumor cells express high levels of proton pumps, including $\mathrm{H}^{+} / \mathrm{K}^{+}$-ATPases and V-ATPase $(16,19,34,35)$. Thus, PPIs, which target the acidic tumor mass, block proton trafficking and represent a class of drugs suitable for this purpose (19). In the present study, we used a primary antibody against the $\mathrm{H}^{+} / \mathrm{K}^{+}$-ATPase B-subunit (ATP4B), and specific bands at $\sim 70 \mathrm{kDa}$ were detected in both MM1.S and MM1.R cells (Fig. 5A). This result indicated that BMT-1 may have intracellular compartments as their sites of action, thus causing $\mathrm{H}^{+} / \mathrm{K}^{+}$-ATPase inhibition. This $\mathrm{H}^{+} / \mathrm{K}^{+}$-ATPase inhibition subsequently triggered rapid cell apoptosis as a result of intracellular acidification, mitochondrial depolarization and caspase activation. Collectively, our data also showed that BMT-1-induced apoptosis was associated with the activation of caspase- $3,-8$ and -9 , as determined by the appearance of the processed forms by western blotting (Fig. 4B). These findings indicate the involvement of caspases in BMT-1-induced apoptosis in MM cells.

In conclusion, our data suggest that BMT-1 is an effective anticancer agent. BMT-1 causes mitochondrial-dependent apoptosis, as indicated by sequential events including $\mathrm{H}^{+} / \mathrm{K}^{+}$-ATPase inhibition, intracellular acidification, mitochondrial depolarization and activation of caspase-9, -8 and -3 (Fig. 5D). We believe that our data contribute to the development of benzimidazole derivatives as lead compounds for the design and development of new agents for the treatment of cancer.

\section{Acknowledgements}

This study was supported by grants from the National Natural Science Foundation of China (nos. 81201668, 81273530, 81302786), from the Sichuan Youth Science and Technology 
Fund (no. 2010JQ0035), from the Scientific Research Fund of Sichuan Provincial Education Department (nos. 11ZA201 and 11ZB169), from the Science and Technology Bureau of Sichuan Province (no. 2012JY0031), from the Foundation of Chengdu Military General Hospital (nos. 2011YG-B02 and 2013YG-A004), from the Research Fund of Chengdu Medical College (CYZ12-001), from the Scientific Research Fund of Sichuan Provincial Health Department (130308), from the National Undergraduates Innovating Experimentation Project (201313705008) and from the Sichuan Province Undergraduates Innovating Experimentation Project (201313705008).

\section{References}

1. Kyle RA and Rajkumar SV: Criteria for diagnosis, staging, risk stratification and response assessment of multiple myeloma. Leukemia 23: 3-9, 2009.

2. Mahindra A, Laubach J, Raje N, Munshi N, Richardson PG and Anderson $\mathrm{K}$ : Latest advances and current challenges in the treatment of multiple myeloma. Nat Rev Clin Oncol 9: 135-143, 2012.

3. Jáuregui I, García-Lirio E, Soriano AM, Gamboa PM and Antépara I: An overview of the novel H1-antihistamine bilastine in allergic rhinitis and urticaria. Expert Rev Clin Immunol 8: $33-41,2012$.

4. Wexler RR, Greenlee WJ, Irvin JD, et al: Nonpeptide angiotensin II receptor antagonists: the next generation in antihypertensive therapy. J Med Chem 39: 625-656, 1996.

5. Navarrete-Vázquez G, Cedillo R, Hernández-Campos A, et al: Synthesis and antiparasitic activity of 2-(trifluoromethyl)-benzimidazole derivatives. Bioorg Med Chem Lett 11: 187-190, 2001

6. Sachs G, Shin JM, Vagin O, Lambrecht N, Yakubov I and Munson K: The gastric H,K ATPase as a drug target: past, present, and future. J Clin Gastroenterol 41 (Suppl 2): S226-S242, 2007.

7. Kim SK, Ahn CM, Choi SJ, Park YS, Cho HC and Koh CM: The growth inhibitiory effect of new pyrrolo[1,2- $\alpha]$ benzimidazole derivatives on human gastric cancer cells. Arch Pharm Res 20: 410-413, 1997.

8. Grimaudo S, Tolomeo M, Chimirri A, Zappala M, Gancitano RA and D'Alessandro N: Selective induction of apoptosis in multidrug resistant HL60R cells by the thiazolobenzoimidazole derivative 1-(2,6-difluorophenyl)- $1 H, 3 H$-thiazolo [3,4-a] benzimidazole (TBZ). Eur J Cancer 34: 1756-1763, 1998

9. Al-Douh MH, Sahib HB, Osman H, Abd Hamid S and Salhimi SM: Anti-proliferation effects of benzimidazole derivatives on HCT-116 colon cancer and MCF-7 breast cancer cell lines. Asian Pac J Cancer Prev 13: 4075-4079, 2012.

10. Youssef AM, Malki A, Badr MH, Elbayaa RY and Sultan AS: Synthesis and anticancer activity of novel benzimidazole and benzothiazole derivatives against HepG2 liver cancer cells. Med Chem 8: 151-162, 2012.

11. Lin ML, Chen SS, Lu YC, et al: Rhein induces apoptosis through induction of endoplasmic reticulum stress and $\mathrm{Ca}^{2+}$-dependent mitochondrial death pathway in human nasopharyngeal carcinoma cells. Anticancer Res 27: 3313-3322, 2007.

12. Shin JM and Kim N: Pharmacokinetics and pharmacodynamics of the proton pump inhibitors. J Neurogastroenterol Motil 19: 25-35, 2013.

13. Webb BA, Chimenti M, Jacobson MP and Barber DL: Dysregulated pH: a perfect storm for cancer progression. Nat Rev Cancer 11: 671-677, 2011.

14. Chen M, Zou X, Luo H, et al: Effects and mechanisms of proton pump inhibitors as a novel chemosensitizer on human gastric adenocarcinoma (SGC7901) cells. Cell Biol Int 33: 1008-1019, 2009.

15. McCarty MF and Whitaker J: Manipulating tumor acidification as a cancer treatment strategy. Altern Med Rev 15: 264-272, 2010.

16. Fais S: Proton pump inhibitor-induced tumour cell death by inhibition of a detoxification mechanism. J Intern Med 267: 515-525, 2010 .
17. Monks A, Scudiero D, Skehan P, et al: Feasibility of a high-flux anticancer drug screen using a diverse panel of cultured human tumor cell lines. J Natl Cancer Inst 83: 757-766, 1991.

18. Karali N: Synthesis and primary cytotoxicity evaluation of new 5-nitroindole-2,3-dione derivatives. Eur J Med Chem 37: 909-918, 2002.

19. De Milito A, Iessi E, Logozzi M, et al: Proton pump inhibitors induce apoptosis of human B-cell tumors through a caspase-independent mechanism involving reactive oxygen species. Cancer Res 67: 5408-5417, 2007.

20. Nilsson C, Kågedal K, Johansson U and Ollinger K: Analysis of cytosolic and lysosomal $\mathrm{pH}$ in apoptotic cells by flow cytometry. Methods Cell Sci 25: 185-194, 2003.

21. Cowling V and Downward J: Caspase-6 is the direct activator of caspase- 8 in the cytochrome $c$-induced apoptosis pathway: absolute requirement for removal of caspase- 6 prodomain. Cell Death Differ 9: 1046-1056, 2002.

22. Chen M, Guerrero AD, Huang L, et al: Caspase-9-induced mitochondrial disruption through cleavage of anti-apoptotic BCL-2 family members. J Biol Chem 282: 33888-33895, 2007.

23. Perry SW, Norman JP, Barbieri J, Brown EB and Gelbard HA: Mitochondrial membrane potential probes and the proton gradient: a practical usage guide. Biotechniques 50: 98-115, 2011.

24. Smolka AJ, Goldenring JR, Gupta S and Hammond CE: Inhibition of gastric $\mathrm{H}, \mathrm{K}-\mathrm{ATPase}$ activity and gastric epithelial cell IL-8 secretion by the pyrrolizine derivative ML 3000. BMC Gastroenterol 4: 4, 2004.

25. Morii M, Takata H, Fujisaki H and Takeguchi N: The potency of substituted benzimidazoles such as E3810, omeprazole, Ro 18-5364 to inhibit gastric $\mathrm{H}^{+}, \mathrm{K}^{+}$-ATPase is correlated with the rate of acid-activation of the inhibitor. Biochem Pharmacol 39: 661-667, 1990.

26. Beil W and Sewing KF: Inhibition of partially purified $\mathrm{K}^{+} / \mathrm{H}^{+}$-ATPase from guinea-pig isolated and enriched parietal cells by substituted benzimidazoles. Br J Pharmacol 82: 651-657, 1984.

27. Yeo M, Kim DK, Park HJ, Cho SW, Cheong JY and Lee KJ: Blockage of intracellular proton extrusion with proton extrusions with proton pump inhibitor induces apoptosis in gastric cancer. Cancer Sci 99: 185, 2008

28. Pinto MC, Dias DF, Del Puerto HL, et al: Discovery of cytotoxic and pro-apoptotic compounds against leukemia cells: Tert-butyl-4-[(3-nitrophenoxy) methyl]-2,2-dimethyloxazolidine-3-carboxylate. Life Sci 89: 786-794, 2011.

29. Chang WL, Chang CS, Chiang PC, et al: 2-Phenyl-5(pyrrolidin-1-yl)-1-(3,4,5-trimethoxybenzyl)-1H-benzimidazole, a benzimidazole derivative, inhibits growth of human prostate cancer cells by affecting tubulin and c-Jun N-terminal kinase. $\mathrm{Br}$ J Pharmacol 160: 1677-1689, 2010.

30. Liu JF, Huang YL, Yang WH, Chang CS and Tang $\mathrm{CH}$ : 1-Benzyl-2-phenylbenzimidazole (BPB), a benzimidazole derivative, induces cell apoptosis in human chondrosarcoma through intrinsic and extrinsic pathways. Int J Mol Sci 13: 16472-16488, 2012.

31. Vasaitis T, Belosay A, Schayowitz A, et al: Androgen receptor inactivation contributes to antitumor efficacy of $17 \alpha$-hydroxylase/17,20-lyase inhibitor $3 \beta$-hydroxy-17- $(1 \mathrm{H}$ benzimidazole-1-yl)androsta-5,16-diene in prostate cancer. Mol Cancer Ther 7: 2348-2357, 2008.

32. Liu JF, Chang CS, Fong YC, Kuo SC and Tang CH: FPipTB, a benzimidazole derivative, induces chondrosarcoma cell apoptosis via endoplasmic reticulum stress and apoptosis signalregulating kinase 1. Mol Carcinog: May 18, 2011 (Epub ahead of print).

33. Schultz BE and Chan SI: Structures and proton-pumping strategies of mitochondrial respiratory enzymes. Annu Rev Biophys Biomol Struct 30: 23-65, 2001.

34. Murakami T, Shibuya I, Ise T, et al: Elevated expression of vacuolar proton pump genes and cellular $\mathrm{pH}$ in cisplatin resistance. Int J Cancer 93: 869-874, 2001.

35. Streif D, Iglseder E, Hauser-Kronberger C, Fink KG, Jakab M and Ritter M: Expression of the non-gastric $\mathrm{H}^{+} / \mathrm{K}^{+}$ATPase ATP12A in normal and pathological human prostate tissue. Cell Physiol Biochem 28: 1287-1294, 2011. 